\title{
Bond-slip law and short tie behavior without main cracks
}

\author{
Djillali Mezhoud ${ }^{\mathrm{a}}$, Youcef Bouafia ${ }^{\mathrm{b}}$, Mohammed Saad ${ }^{\mathrm{b}}$ and Jacqueline Saliba ${ }^{\mathrm{c}}$ \\ aLaboratoire de Génie de la Construction et Architecture (LGCA), Faculté de Technologie, Université de Bejaia, \\ Bejaia, Algérie; 'baboratoire LaMoMs, Université Mouloud Mammeri de Tizi-Ouzou, Tizi-Ouzou, Algérie; \\ 'Département Génie Civil et Environnemental (GCE), Institut de Mécanique et d'ingénierie (I2M), Université \\ de Bordeaux, Bordeaux, Talence, France
}

\section{ABSTRACT}

The aim of this paper is to study the reinforced concrete short tie-rods behavior using the adhesionslip curve shape between steel and concrete adopted by the European Concrete Committee. We are interested here in short tie-rods without main cracks for which we calculate and measure the maximum mobilization state of steel-concrete adhesion, and beyond the decrease mode of this bond. For this, tests of short tie-rods, with different high adhesion rebar diameters have been carried out. To characterize the first phase of the adhesion-slip behavior law $(\tau-g)$, pull out tests have been carried out with the same concrete, the same reinforcement and the same cross-section such as the tie-rod tests, with a proposed method to estimate the adhesion peak and the corresponding slip. For this adhesion peak value, slightly underestimated by the conventional curve of the European Concrete Committee, a new expression is suggested. A numerical model with theoretical relations of the behavior of such tie-rods is proposed. The comparison of this model with the obtained test curves of the short tie-rods shows a suitable approach. Also, we deduce that the steel (coated with concrete) fictitious module slope is even higher than the percentage of reinforcement is low. These results may help to understand the tie-rods behavior generally, in the phase of cracks stabilization, during which the tie-rod is composed of short tierods without main cracks.

\section{Introduction}

During dimensioning reinforced concrete structural elements (Reinforcement and stress testing), the contribution of tensioned concrete is totally neglected, which is sufficient in this case. However, for practical reasons, consideration should be given to:

- The estimation of the crack openings in the service limit state (SLS).

- The calculation of the mean rigidity of the tie rod to correctly evaluate the deformations at the SLS and even at the ultimate limit state (ULS) during the redistribution of forces in the hyperstatic structures (Effects of second order in shape stability and the response in alternating stresses). 
Numerous studies have been carried out to evaluate the contribution of tensed concrete between cracks. Two types of approach are considered:

- The distribution hypothesis of the adhesion along the tie-rod, without involving the sliding [1].

- Using the equilibrium of forces and the compatibility of deformations from experimental relationships, such as the model of the European Concrete Committee [2], between the local stress of steel/concrete adhesion and the corresponding slip, to lead at the resolution of differential equations [3-5].

To express the solution of the problem, two types of formulation are distinguished:

- Mean fictitious behavioral laws of taut concrete, taking into account the addition of the reinforcement and concrete contributions to the cross section of the 'tie rod' [6-9].

- Fictitious behavioral laws of tensile steel (concrete-coated steel), implicitly taking into account tensed concrete in the form of a corrective term (Relative elongation deviation $\Delta \varepsilon$, between bare steel and concrete-coated steel for the same tensile force) [10-12].

Many studies have been carried out on the concrete steel connection, with series of experimental tests [13-16], mostly, the study of the geometry influence of the ribs on the resistance and rigidity [14] and the effects of passive and active confinement on the maximum stress of the bond [15]. Other studies propose models of local adhesion-slip relationships $[13,17,18]$. Several authors have investigated the behavior and estimation of crack openings [19-21] in the tie rods, and especially during the phase of stabilization of these cracks. During this last phase, the tie rod is composed of several 'short tie rods'. The study of these latter makes it possible to understand how the forces redistribution is effected and the evolution of widths of crack openings because limited to the limit state of service by the different regulations around the world evolve [22].

The contribution of concrete, through experimental relations, is expressed here by fictitious behavior laws of steel in tension for short ties without major cracks.

To do this, pull out tests with different reinforcement diameters of high adhesion have been carried out to characterize the first phase of the law of stress-slip behavior $(\tau-g)$ between steel and concrete. Short ties specimens were made with the same concrete, the same cross-section with varying the steel rebar's diameter.

The adhesion-slip curve is obtained through pull-out tests [18,23-25] in order to characterize the curvilinear curve.

Tests on short ties, whose lengths are chosen so that no major cracks appear, will help us to better understand the mode of variation of the mobilization of steel/concrete adhesion and to propose behavior laws of steel in tension for such elements.

The behavior of short ties without major cracks also makes it possible to understand the response of tie rods in general [26]. In this work, the short ties without cracks highlight according to the loading and characteristics of the two materials the moment when a maximum mobilization of the adhesion is obtained. From this moment, it is interesting to see how this adhesion between steel and concrete decreases. This last observation makes it possible to understand the decrease of the contribution of the concrete after the stabilization of the cracks in a tie rod. 


\section{Curves $(\tau-g)$ between steel and concrete adopted by the European}

\section{Concrete Committee}

The European Concrete Committee [2] adopted the stress-sliding relations 1, 2, 3 and 4 between steel and concrete. These curves (Figure 1) are derived from standardized steel bar coated with concrete pull out tests.

$$
\begin{array}{lr}
\tau=\tau_{1}\left(\frac{g}{g_{1}}\right)^{\alpha} & \text { if } 0 \leq g \leq g_{1} \\
\tau=\tau_{1} & \text { if } g_{1} \leq g \leq g_{2} \\
\tau=-\frac{\tau_{1}-\tau_{3}}{g_{3}-g_{2}} g+\frac{\tau_{1} g_{3}-\tau_{3} g_{2}}{g_{3}-g_{2}} & \text { if } g_{2} \leq g \leq g_{3} \\
\tau=\tau_{r} & \text { if } g \geq g_{3}
\end{array}
$$

The value of $\alpha$ is between 0.25 and 0.40 depending on the confinement of the concrete. The adhesion peak $\tau_{1}$ is taken as:

$$
\tau_{1}=a \sqrt{f_{c k}}
$$

With $a=2.5$ for a confined concrete, otherwise $a=2$

The normal compressive stress limit of the concrete $f_{c k}$ is expressed in MPa. The value of the residual stress $\tau_{r}$ is taken equal to $0.20 \tau_{1}$.

If the modeled curve (Figure 1) of the different phases seems rather representative, the intervals of variation of the different slips $\left(g_{1}, g_{2}\right.$ and $\left.g_{3}\right)$ are closer to those given by Eligehausen [27].

These results (curves until adhesion depletion) are possible only if the percentage of steel in the concrete is very low, generally lower than the minimum ratio allowed by the various regulations around the world. For common cases [5,28], only the first curve (Figure 1) (relation 1) is effective.

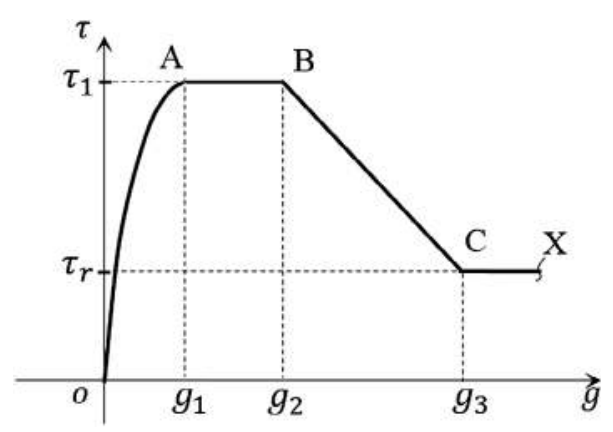

Figure 1. $\tau-g$ Curves adopted by the CEB. 


\section{Variation mode of stresses-deformations of short tie rods $\left(\sigma_{s}-\varepsilon_{t}\right)$}

An analytical method is developed in this paper in order to study the short ties behavior based on the experimental results.

A short tie with a length $\left(l_{t}=2 L\right)$, a section $A_{t}(a \times a)$ constant along the tie and a centered rebars section $A_{s}$, is considered and subjected to a variable tensile load $N_{t}$ (Figure 2).

The normal stress $\sigma_{c}(x)$ in the concrete (with a Young Modulus $E_{c}$ ) is considered uniformly distributed and the normal stress in steel $\sigma_{s}(x)$ (with a modulus of elasticity $E_{s}$ ) remains lower to elastic stress of steel $\sigma_{e}$.

Figure 3 shows the normal stress-relative strain diagram $(\sigma-\varepsilon)$ of the tie rod where $\varepsilon_{t}$ represents the relative elongation of the tie rod and $\Delta \varepsilon_{s}$ the difference with the bare steel under the same normal stress $\sigma_{s n}=N_{t} / A_{s}$.

The rebar is embedded in the concrete and the origin of the abscissa is considered at the point $\mathrm{O}$ (Figure 4(a) and (b)). It is clear that, after the application of the load $N_{t}$, which is relatively small, the adhesion stress increases until it reaches a maximum, then decreases to zero at the abscissa $l_{1}$, called introductory length, (Figure $4(\mathrm{c})$ ). We suppose that the maximum of $\tau$ is located at the ends of the tie rod, Figure 4(d).

The normal stress in steel rebar and the relative elongation corresponding to the ends of the tie are denoted respectively $\sigma_{s n}$ and $\varepsilon_{s n}$. The normal stress in steel is variable along $l_{1}, \sigma_{s 1}\left(\varepsilon_{s 1}\right)$, and constant along $L-l_{1}, \sigma_{s 2}\left(\varepsilon_{s 2}\right)$, Figure $4(\mathrm{e})$. Respectively, we have for concrete along $l_{1}, \sigma_{c 1}\left(\varepsilon_{c 1}\right)$ and for $L-l_{1}, \sigma_{c 2}\left(\varepsilon_{c 2}\right)$.

Here the concrete length is not long enough so that the mobilization of the adhesion allows to create a crack, (relation 6).

$$
\int_{L} \tau(x) \cdot p \cdot \mathrm{d} x<A_{c} \cdot f_{\mathrm{ctm}}
$$

With: $f_{\mathrm{ctm}}$ : Resistance (average) to effective tensile strength of the concrete; $A_{c}$ : Net section of concrete subjected to tension $\left(A_{c}=A_{t}-A_{s}\right)$.

\subsection{Variation of the relative elongation of steel over the length $I_{1}$ of the tie rod}

With $(p)$ the useful perimeter of the steel section and $n=E_{s} / E_{c}$, the variations of the relative elongations of steel and concrete along the length $l_{1}$ are written respectively:

$$
\varepsilon_{s 1}(x)=\varepsilon_{s n}-\frac{p}{A_{s} \cdot E_{s}} \int_{0}^{x} \tau(\xi) \cdot \mathrm{d} \xi \quad \varepsilon_{c 1}(x)=\frac{p}{A_{s} \cdot E_{s}} \cdot \frac{n \cdot \rho}{(1-\rho)} \int_{0}^{x} \tau(\xi) \cdot \mathrm{d} \xi
$$

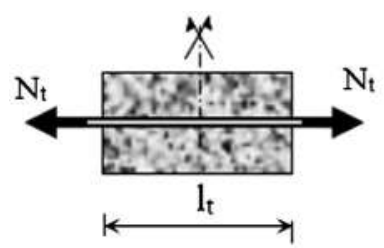

(a)

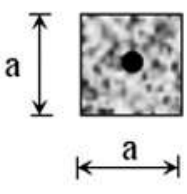

(b)

Figure 2. Short tie-rod, (a) View full length, (b) Straight section. 


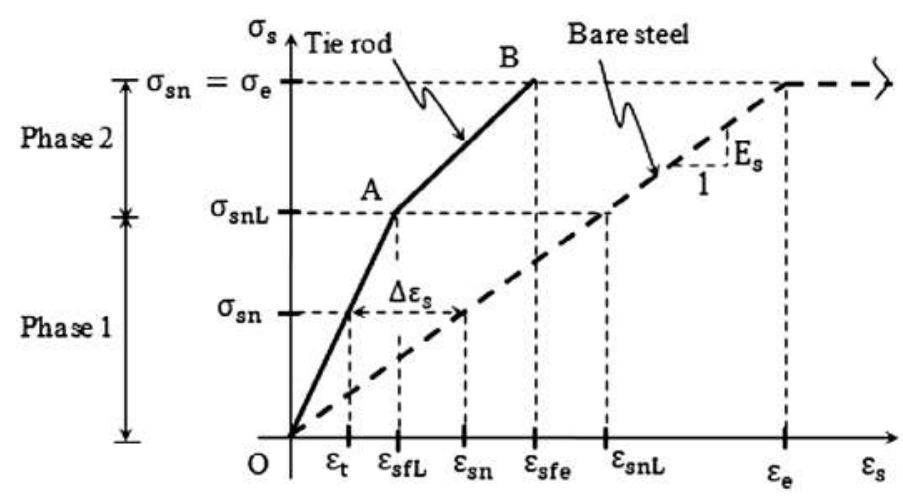

Figure 3. Diagram type $\sigma-\varepsilon$ of the short tie.
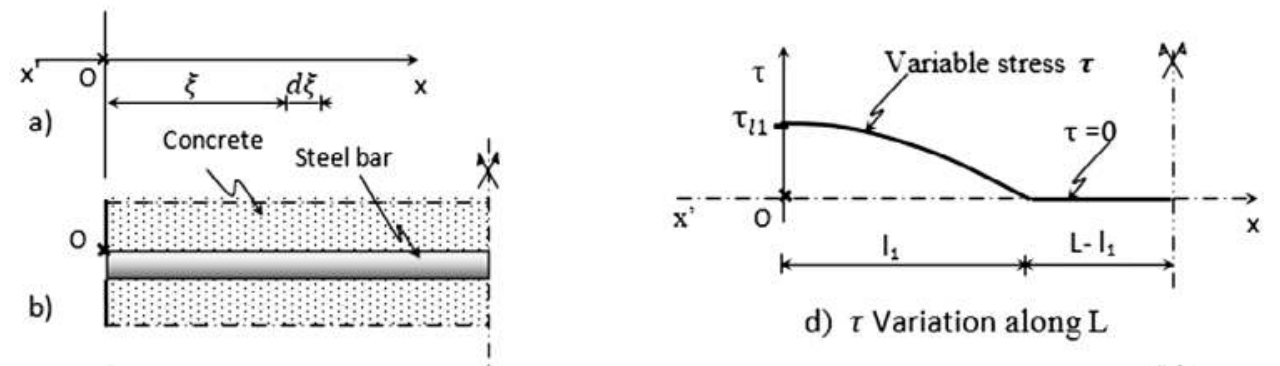

d) $\tau$ Variation along $\mathrm{L}$
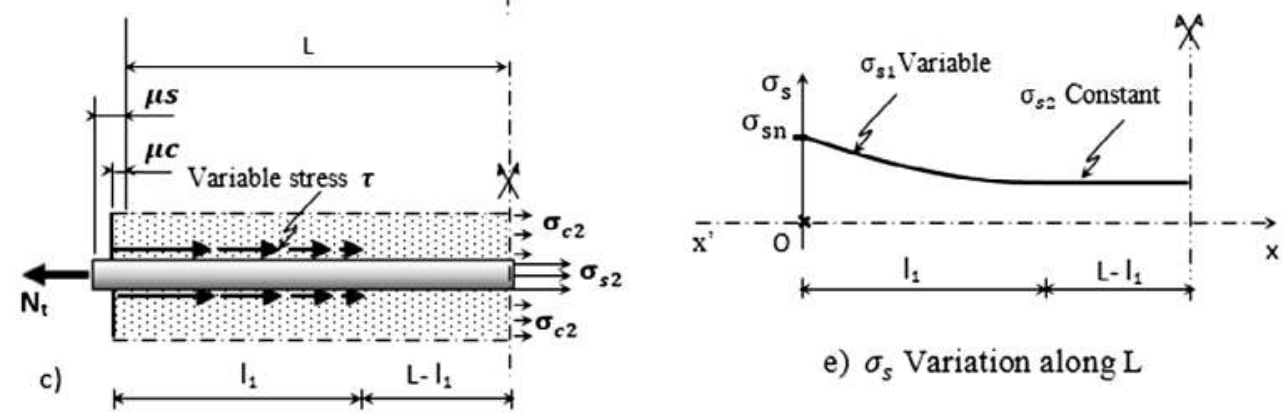

e) $\sigma_{s}$ Variation along $\mathrm{L}$

Figure 4. Slipping between steel and concrete and stresses generated under $N_{t}$ in the tie.

For the two intervals of length $l_{1}$ on either side of the tie rod expressing the equilibrium of strength and the expression of the slip $g$ between the elongations of steel $u_{s}$ and concrete $u_{c}, g(x)=u_{c}(x)-u_{s}(x)$. We can write:

$$
\frac{\mathrm{d} g}{\mathrm{~d} x}=\frac{\mathrm{d} u_{c}}{\mathrm{~d} x}-\frac{\mathrm{d} u_{s}}{\mathrm{~d} x}=\varepsilon_{c}(x)-\varepsilon_{s}(x) \quad \Rightarrow \quad \frac{\mathrm{d}^{2} g}{\mathrm{~d} x}=\frac{\mathrm{d} \varepsilon_{c}}{\mathrm{~d} x}-\frac{\mathrm{d} \varepsilon_{s}}{\mathrm{~d} x}
$$

And the differential equation 7 can be obtained:

$$
\frac{\mathrm{d}^{2} g(x)}{\mathrm{d} x^{2}}-\frac{p}{A_{s} \cdot E_{s} \cdot \bar{\rho}} \tau(x)=0 \quad \text { Where } \quad \bar{\rho}=\frac{1}{1+\frac{n \cdot \rho}{(1-\rho)}}, \quad \rho=\frac{A_{s}}{A_{t}}
$$


The relation 8 represents the solution of the differential equation $[3,4,12]$, and the variation of the bond stress $\tau$ can be deduced

$$
\begin{gathered}
g(x)=\theta^{1 /(1-\alpha)}\left[l_{1}-x\right]^{2 /(1-\alpha)} \\
\text { where } \theta=\frac{\beta_{1}^{2}(1-\alpha)^{2}}{2(1+\alpha)}, \quad \beta_{1}=\sqrt{\frac{k_{1} \cdot p}{A_{s} \cdot E_{s} \cdot \bar{\rho}}}, \quad k_{1}=\frac{\tau_{1}}{g_{1}^{\alpha}}
\end{gathered}
$$

The variation of the adhesion along $l_{1}$ and its maximum at the extremities $\tau_{l 1}$ for $x=0$ are written by expressions 9 and 10 .

$$
\begin{gathered}
\tau(x)=k_{1} \theta^{\alpha /(1-\alpha)}\left[l_{1}-x\right]^{2 \alpha /(1-\alpha)} \\
\tau_{l 1}=k_{1} \theta^{\alpha /(1-\alpha)} l_{1}^{2 \alpha /(1-\alpha)}
\end{gathered}
$$

Thus, the normal stress exerted at the ends of the tie-rod (nude steel), replaced by its longitudinal relative deformation $\varepsilon_{s n}\left(\frac{\mathrm{d} g}{\mathrm{~d} x_{x=0}}=\varepsilon_{s n}\right)$ can be written as:

$$
\varepsilon_{s n}=\frac{2}{(1-\alpha)} \cdot \theta^{1 /(1-\alpha)} l_{1}^{(1+\alpha) /(1-\alpha)}
$$

The variation of the longitudinal relative deformation $\varepsilon_{s 1}$ of the steel along the length $l_{1}$ is deduced and after simplification we obtain the expression 12:

$$
\begin{gathered}
\varepsilon_{s 1}(x)=\varepsilon_{s n}-\frac{p}{A_{s} \cdot E_{s}} \int_{0}^{x} \tau(\xi) \cdot \mathrm{d} \xi=\varepsilon_{s n}-\frac{p}{A_{s} \cdot E_{s}} \int_{0}^{x} k_{1} \theta^{\alpha /(1-\alpha)}\left[l_{1}-\xi\right]^{2 \alpha /(1-\alpha)} \cdot \mathrm{d} \xi \\
\varepsilon_{s 1}(x)=\left[1-\bar{\rho}+\bar{\rho}\left(1-\frac{x}{l_{1}}\right)^{(1+\alpha) /(1-\alpha)}\right] \varepsilon_{s n} \quad \text { for } 0<x \leq l_{1}
\end{gathered}
$$

\subsection{Variation of the relative elongation of the steel over the length $\left(L-I_{1}\right)$ of the} tie rod

At the distance $x$, comprised in the interval $\left[l_{1} ; L\right]$ the behavior of the tie-rod is homogeneous, concrete and steel resist together to balance the stress $N_{t}$. There is compatibility in the deformations $\left(\varepsilon_{c 2}=\varepsilon_{s 2}\right)$ and the sliding between the reinforcement and the concrete is equal to zero $\left(u_{s}=u_{c}\right)$. We may write, in any straight section of this interval of the tie-rod:

$$
\begin{gathered}
N_{t}=\sigma_{c 2}\left(A_{t}-A_{s}\right)+\sigma_{s 2} \cdot A_{s}=\sigma_{c 2}\left(A_{t}-A_{s}\right)+n \cdot \sigma_{c 2} \cdot A_{s} \\
\frac{N_{t}}{A_{s}}=\sigma_{s n}=E_{s} \cdot \varepsilon_{s n}=E_{c} \cdot \varepsilon_{c 2}\left(n+\frac{1-\rho}{\rho}\right)=E_{c} \cdot \varepsilon_{s 2}\left(n+\frac{1-\rho}{\rho}\right)=E_{s} \cdot \varepsilon_{s 2}\left(1+\frac{1-\rho}{n \cdot \rho}\right)
\end{gathered}
$$




$$
\frac{N_{t}}{A_{s}}=E_{s} \cdot \varepsilon_{s n}=\frac{E_{s}}{(1-\bar{\rho})} \varepsilon_{s 2}
$$

This gives the relation 13 which represents the constant relative elongation of the steel over the length $\left(L-l_{1}\right)$.

$$
\varepsilon_{s 2}=(1-\bar{\rho}) \cdot \varepsilon_{s n} \quad \text { for }\left(L-l_{1}\right)
$$

\subsection{Proposition of a behavior law of short tie-rods $(\sigma-\varepsilon)$}

With theoretical results above and observations made by several authors on the slip between steel and concrete at the beginning of loading, we propose here laws of behavior $\sigma-\varepsilon$ of the short tie rods.

This is in agreement with the study conducted by Giuriani [29] who showed that the sliding is effective for the spline bars only after a certain pulling force, and thus the $\tau-g$ curve does not pass through the origin of the abscissa $g$.

Eligehaussen \& al [27] reported that the slope of the curve is relatively high at the beginning. By increasing the pulling force of the bar, the ribs of the steel rebar abut on the concrete and begin to crush it. At this moment, the first cracks appear and the slip at this stage is relatively small (point A in Figure 5). The partial shearing of concrete rods results in a reduction in the slope between point $\mathrm{A}$ and $\mathrm{B}$. The point $\mathrm{C}$ represents the moment when the maximum adhesion stress is obtained if the confinement is sufficient. Then the residual stress decreases due to the friction along the sheared concrete zone in the descending branch.

For our study, with relations 12, 13 and Figures 3 and 4, assuming a linear variation of $\sigma-\varepsilon$ curve of short tie, the diagrams slopes (minimum and maximum) can be deduced for phase 1 . With relation 12 , when $l_{1}=L$, we obtain the minimum slope:

$$
\left\{\begin{array}{lll}
\varepsilon_{s 1}=\varepsilon_{s n} & \text { if } & x=0 \\
\varepsilon_{s 1}=(1-\bar{\rho}) \varepsilon_{s n} & \text { if } & x=l_{1}
\end{array}\right.
$$

As a first approximation, we can take the average: $\varepsilon_{s 1}=\left(1-\frac{\bar{\rho}}{2}\right) \varepsilon_{s n}$ and the minimal slope represented by the fictitious module is deduced: $\frac{E_{s}}{1-\frac{\hat{\rho}}{\underline{\rho}}}$

With relation 13 , when $l_{1}$ tends to 0 , we obtain the maximum slope either: $\frac{E_{s}}{1-\bar{\rho}}$

So for the first phase, the dummy module $E_{f 1}$ is equal, relation 14

$$
E_{f 1}=\frac{E_{s}}{\psi_{1}} \quad \text { with }(1-\bar{\rho})<\psi_{1}<\left(1-\frac{\bar{\rho}}{2}\right)
$$

For phase 2, after maximum mobilization of the adhesion between steel and concrete, this bond deteriorates and only a residual adhesion remains, in this case it is possible to take as fictitious module $E_{f 2}$, relation 15

$$
E_{f 2}=\frac{E_{s}}{\psi_{2}} \quad \text { with } 0,8<\psi_{2}<0,9
$$



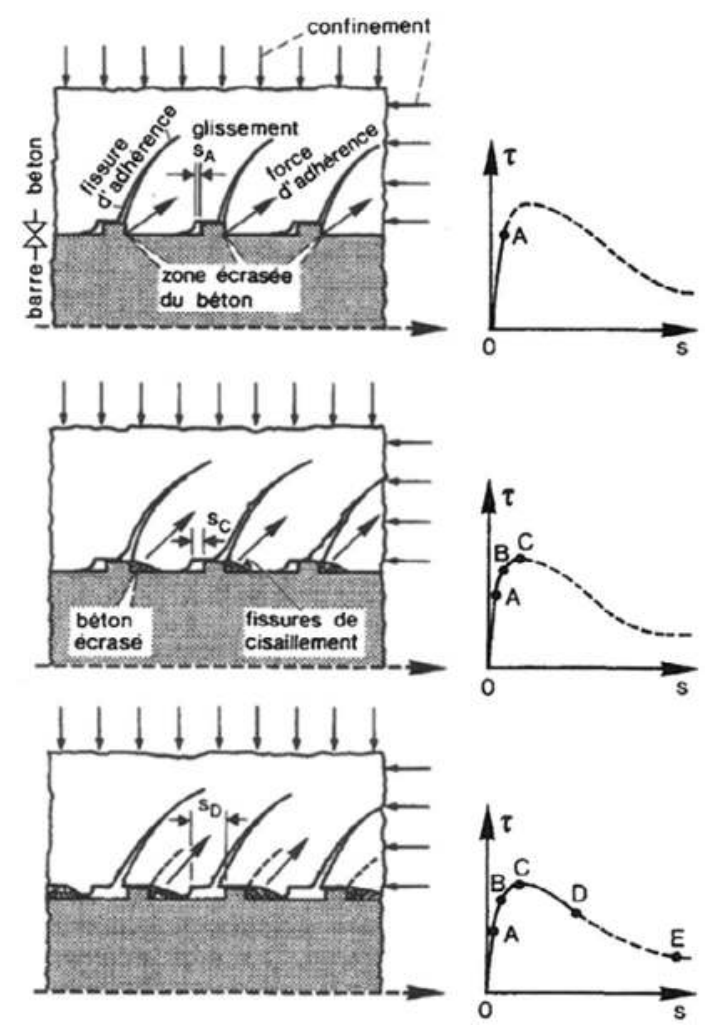

Figure 5. Adhesion mechanism and diagram from the full bond-sliding relationship according to Eligehausen et al. [27].

The $\psi_{1}$ and $\psi_{2}$ values are less than unity and will be estimated after carrying out the experimental tests.

The curve $\sigma-\varepsilon$ limit points of the short tie rods are A and B Figure 3.

At point $\mathrm{A}$, at maximum mobilization of adhesion $\left(l_{1}=L\right)$, Figure $4(\mathrm{e})$ and using relation 11 , the relative elongation of bare steel is written, expression 16.

$$
\varepsilon_{s n L}=\frac{2}{1-\alpha} \cdot \theta^{1 /(1-\alpha)} L^{(1+\alpha)_{/}(1-\alpha)}
$$

We have also: $\sigma_{s n L}=E_{s} \varepsilon_{s n L}$

In our study, the normal stress in steel is limited to $\sigma_{e}$ (also $\varepsilon_{e}$ ) corresponding to the fictional relative elongation of steel $\varepsilon_{s f e}$ represented by point B, Figure 3 and determined by relation 17 .

$$
\varepsilon_{s f e}=\frac{\sigma_{e}-\sigma_{s n L}}{E_{f 2}}+\varepsilon_{s f L} \quad \text { with } \quad \varepsilon_{s f L}=\frac{\sigma_{s n L}}{E_{f 1}}
$$


In summary, for the short tie-rods, at the elastic limit of concrete, the relation 18 represents the fictitious diagram $\sigma-\varepsilon$ of the steel:

$$
\left\{\begin{array}{llr}
\sigma=E_{f 1} \cdot \varepsilon & \text { if } & 0 \leq \varepsilon \leq \varepsilon_{s f L} \\
\sigma=E_{f 2} \cdot\left(\varepsilon-\varepsilon_{s f L}\right)+\sigma_{s n L} & \text { if } & \varepsilon_{s f L} \leq \varepsilon \leq \varepsilon_{s f e}
\end{array}\right.
$$

\section{Materials}

\subsection{Concrete}

The particle size analysis was carried out according to the French standard NF P 18-560 (Table 1 ), with a maximum diameter, $D_{\max }=12.5 \mathrm{~mm}$ for gravel and a fineness module for sand, $M F=2.03$. A single formulation of an ordinary concrete has been used for all series of tests. The composition of the concrete for one cubic meter determined by Faury's method is given in Table 2. The use of large aggregates $(15 / 25)$ was avoided considering the relatively small dimensions of specimens.

Prismatic $(15 \times 15 \times 15) \mathrm{cm}^{3}$ and cylindrical $11 \mathrm{~cm} \times 22.5 \mathrm{~cm}$ specimens have been prepared for compression and tensile tests respectively. The results of the various properties of the concrete are given in Table 3.

\subsection{Steel}

The used rebars for the pull out and the tie rods tests are steels with high rib adhesion (Figure 6). Tensile tests on nude bars of $18 \mathrm{~cm}$ long have been carried out. A yield stress of $\sigma_{e}=530 \mathrm{MPa}$ and a longitudinal elastic modulus of $E_{s}=200 \mathrm{GPa}$ have been calculated for the used diameters $\emptyset=8,12$ and $14 \mathrm{~mm}$.

Note here that the adhesion between steel and concrete depends on the characteristics of the ribs.

The works, of Rehm [30], Sorez \& Hölzenbein [31] as well as Martin \& Noakowski [32] showed the geometric importance of the ribs of rebars in the steel-concrete adhesion.

The Studies carried out by Caetano \& al [33] and Handika \& al [26] showed the influence of the ribs in considering the height $h_{1}$, the spacing $e_{1}$, the angle of the ribs $\alpha_{1}\left(45\right.$ to $\left.50^{\circ}\right)$ and the angle of inclination of the ribs $\alpha_{2}\left(45\right.$ to $\left.50^{\circ}\right)$ (Figure 7 ).

The geometrical characteristics of the ribs of the reinforcement used for our tests are shown in Table 4.

\section{Pull out tests}

Pull-out tests are carried out with the machine shown in Figure 8. They are conducted on the same bars used for the tie rods.

\subsection{Geometry of specimens and procedure (Figures 8 and 9)}

Prismatic specimens with a cross section of $100 \mathrm{~mm} \times 100 \mathrm{~mm}$ and a length of $15 \varphi$ where $\varphi$ is the rebar diameter were used (Figure 9(a)). Reinforced concrete pull out specimens were 


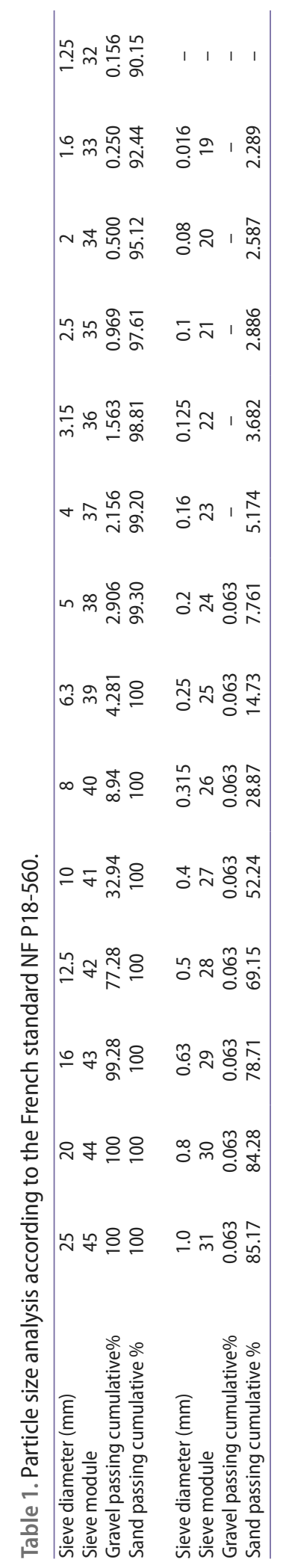


Table 2. Concrete constituents.

\begin{tabular}{lcc}
\hline Sand 0/3 & $629 \mathrm{~kg} / \mathrm{m}^{3}$ & $26.4 \%$ \\
Rolled gravel 3/15 & $1148 \mathrm{~kg} / \mathrm{m}^{3}$ & $48.3 \%$ \\
Cement CEM 32.5 R & $400 \mathrm{~kg} / \mathrm{m}^{3}$ & $16.8 \%$ \\
Water & $202 \mathrm{~kg} / \mathrm{m}^{3}$ & $8.50 \%$ \\
Total & $2379 \mathrm{~kg} / \mathrm{m}^{3}$ & $100 \%$ \\
\hline
\end{tabular}

Table 3. Concrete properties.

Compressive strength at 28 days $\left(f_{c 28}\right)$

Average tensile strength at 28 days $\left(f_{c t m} 28\right)$

Modulus of elasticity of concrete $E$ c

33.7 $\mathrm{MPa}$

Cement/Water ratio $(C / E)$

$2.60 \mathrm{MPa}$

Abrams cone subsidence

$35.5 \mathrm{GPa}$

1.98

$60 \mathrm{~mm}$
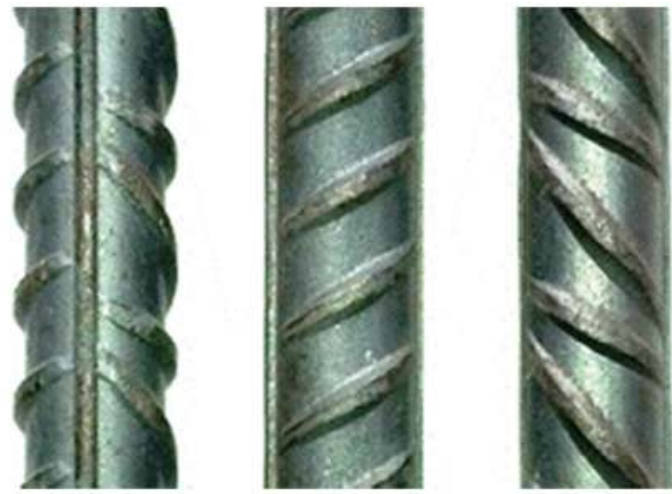

Figure 6. High adhesion steel used.

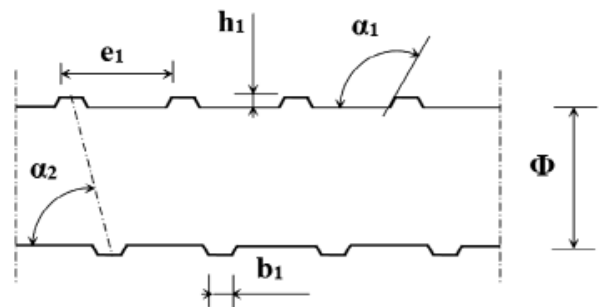

Figure 7. Geometric characteristics of the ribs taken into account by Caetano and al [33].

Table 4. Characteristic values and geometry of the ribs.

\begin{tabular}{lcccc}
\hline$\emptyset(\mathrm{mm})$ & $h_{1}(\mathrm{~mm})$ & $b_{1}(\mathrm{~mm})$ & $e_{1}(\mathrm{~mm})$ & $A_{s}\left(\mathrm{~mm}^{2}\right)$ \\
\hline 8 & 0.7 & 0.9 & 5.3 & 50.3 \\
12 & 1 & 1.2 & 7.2 & 1.13 \\
14 & 1.1 & 1.4 & 8.4 & 1.154 \\
\hline
\end{tabular}




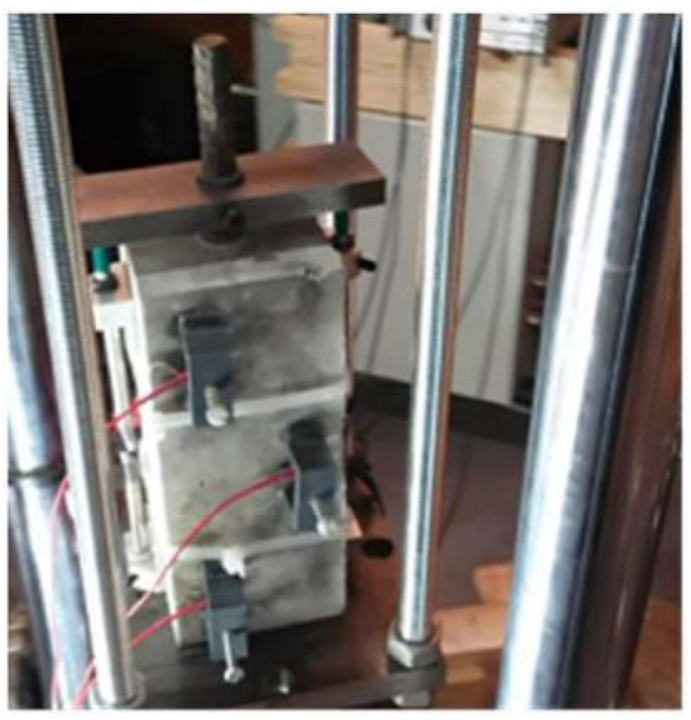

Figure 8. Specimen used and device.
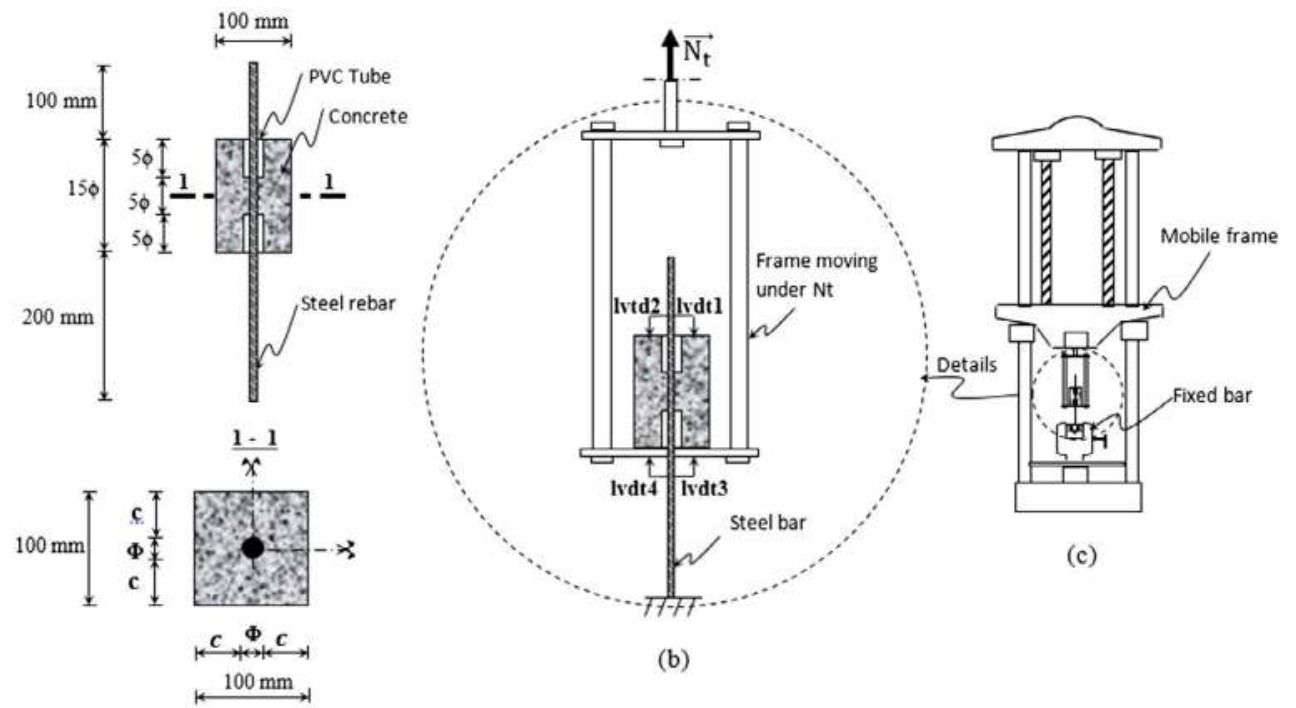

(a)

Figure 9. Specimen and device for the pull-out test, (a) Specimen geometry, (b) Concrete moving frame, (c) Concrete moving frame.

designed with a length varying in function of rebars diameter $\varphi$. Reinforcing steel rods were placed prior to casting of concrete with a protective layer on the bottom and upper side of embedded steel over a length of $5 \varphi$ using a PVC hose covering as shown in Figure 9(a) in order to avoid inaccurate stresses in the specimens and friction in the sample. Rebars are embedded into a $15 \varphi$ concrete cube and the bond length of the steel bar and concrete was equal to5 $\phi$. 
As the section of specimens is kept constant, similar to that of RC tensile tests, the percentage of steel is varied $\rho=A_{s} / A_{t}$ where $A_{s}$ and $A_{t}$ represent respectively the section of the steel and the section of the specimen.

The pulling out and the withdrawal of the reinforcing element from concrete are performed in the axial tensile mode using a testing machine with a special metal framework. The sample was placed in a holder with a stopper fixed at the lower clamp of the testing machine while the free top part of the rod was fixed by the testing machine (Figure $9(b, c)$ ). The sample was loaded by pulling out the rod at a constant velocity in the vertical direction. The loading force and displacement of the mobile clamp were continuously monitored. In addition, two LVDT sensors were placed in order to measure the slip between the rod and concrete on the bottom and the upper side of the sample in order to study any perturbations as flexion.

\subsection{Experimental pull out results}

Pull out tests were realized on reinforced concrete specimens with high adherence rebars HA8, HA12 and HA14 (Three specimens for each type), and thus different percentage of steel $0.50,1.13$ and $1.54 \%$ respectively.

The bond stress slip relationships $(\tau-g)$ are presented in Figure 10 for rebars with different diameters. Tests with the HA14 rebars have broken out and are not shown here.

\subsection{Characteristic values of the adhesion slip law $(\tau-g)$}

Based on the bond stress slip curves obtained in Figure 10 and numerical results, the characteristics of the $\tau-g$ law can be deduced.

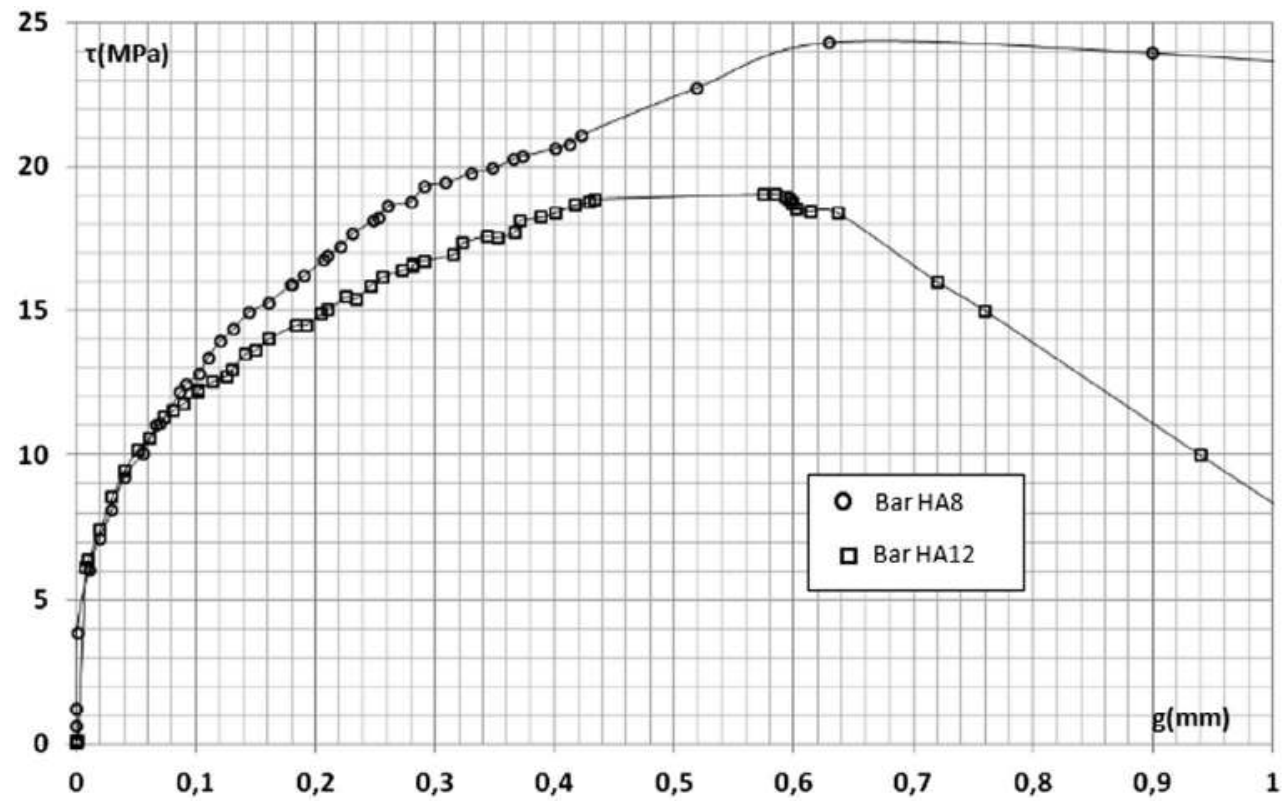

Figure 10. Stress -slip curves. 
Eligehausen \& al [27] law, adopted by the European Concrete Committee [2] is used for the first phase, with the tests values, we can write the expression 19.

$$
\tau=\tau_{1 \max }\left(\frac{g}{g_{1 \max }}\right)^{\alpha}
$$

The value of the confinement $c$ for the tie-rods used here is given by the relation 20:

$$
c=50-\emptyset / 2 \quad \emptyset \text { and } c \text { in } \mathrm{mm}
$$

The value of $\tau_{1 \max }$ is deduced directly from the maximal load obtained with the various pull out tests (Table 5) and the first part of the curvilinear curve at the beginning of loading.

Knowing two states of loading $j\left(g_{j} ; \tau_{j}\right)$ and $k\left(g_{k} ; \tau_{k}\right)$ with the loading level at $k$ superior to that of $j$ and $\tau_{k}>\tau_{j}$ :

$$
\left\{\begin{array}{l}
\tau_{j}=\tau_{1 \max }\left(\frac{g_{j}}{g_{1 \max }}\right)^{\alpha} \\
\tau_{k}=\tau_{1 \max }\left(\frac{g_{k}}{g_{\max }}\right)^{\alpha}
\end{array}\right.
$$

Considering the ratio of $(b)$ to $(a)$, expression 21 can be deduced

$$
\alpha=\frac{\log \left(\tau_{k} / \tau_{j}\right)}{\log \left(g_{k} / g_{j}\right)}=\log \left(\tau_{k} / \tau_{j}\right)-\log \left(g_{k} / g_{j}\right)
$$

When $\alpha$ is determined, and for the state at the beginning of loading $(g ; \tau), g_{1 \max }$ can be deduced by the relation 22 :

$$
g_{\text {max }}=g \cdot\left(\frac{\tau_{1 \max }}{\tau}\right)^{1 / \alpha}
$$

In our case, $\alpha$ was considered equal to 0.33 , the others results are given in Table 5 .

Note: The European Concrete Committee [2] uses here two coefficients $\alpha$ and $a$ to express the same parameter: the confinement of the concrete. To keep only one, knowing that for $\alpha=0.25$ and $\alpha=0.40$ corresponding $a=2$ and $a=2.5$ respectively, the relation 5 can be written:

$$
\tau_{1}=\left(\frac{10}{3} \alpha+\frac{7}{6}\right) \sqrt{f_{c k}}
$$

Table 5. Characteristic values of the $\tau-g$ law deduced from the pull out curves.

\begin{tabular}{lcc}
\hline Diameter of the rebar $\emptyset(\mathrm{mm})$ & HA8 & HA12 \\
\hline Percentage of steel $\left(A_{s} / A_{t}=\right.$ Steel section/Tie-rods section) & $0.503 \%$ & $1.13 \%$ \\
Maximum pull-out load of the bar $(k N), F_{a, \text { max }}$ & 24.4 & 43.0 \\
Normal stress in the rebar $(\mathrm{MPa})$ & 485 & 381 \\
Maximum adhesion stress $\tau_{1 \max }(\mathrm{MPa})$ & 24 & 19 \\
Estimated Value of $\alpha$ & 0.33 & 0.33 \\
Estimation of the maximum slip value, $g_{1 \max }(\mathrm{mm})$ & 0.34 & 0.24 \\
\hline
\end{tabular}


Based on the experimental tests, the conventional curve adopted by the European Concrete Committee [2], underestimated the value of $\tau_{1}$. Therefore, the relation 24 is proposed:

$$
\tau_{1}=(4 . \alpha+1) \sqrt{f_{c k}}
$$

\section{Tests on short tie-rods without main cracks}

\subsection{Specimens dimensions and preparation}

The section of the tie-rods is the same as those of the pull out tests, Figures 9(a). Figure 11 presents a sketch of the short ties, where rebars are placed in the center with a total length of $480 \mathrm{~mm}$. Rebars are embedded into a length of $l_{t}=190 \mathrm{~mm}$ chosen so that no principal cracking can appear during tensile tests. At both end of the RC ties, PVC tubes of $30 \mathrm{~mm}$, are placed in order to avoid inaccurate stresses in the specimens and friction and splitting in the sample. Three specimens were prepared for each type of tie rod (THA8, THA12 and THA14).

\subsection{Operating mode on the tie-rods}

After casting, specimens were covered with a thin sheet of plastic to prevent water loss and were maintained in a climatic chamber at a temperature of $20^{\circ} \mathrm{C}$ and a relative humidity

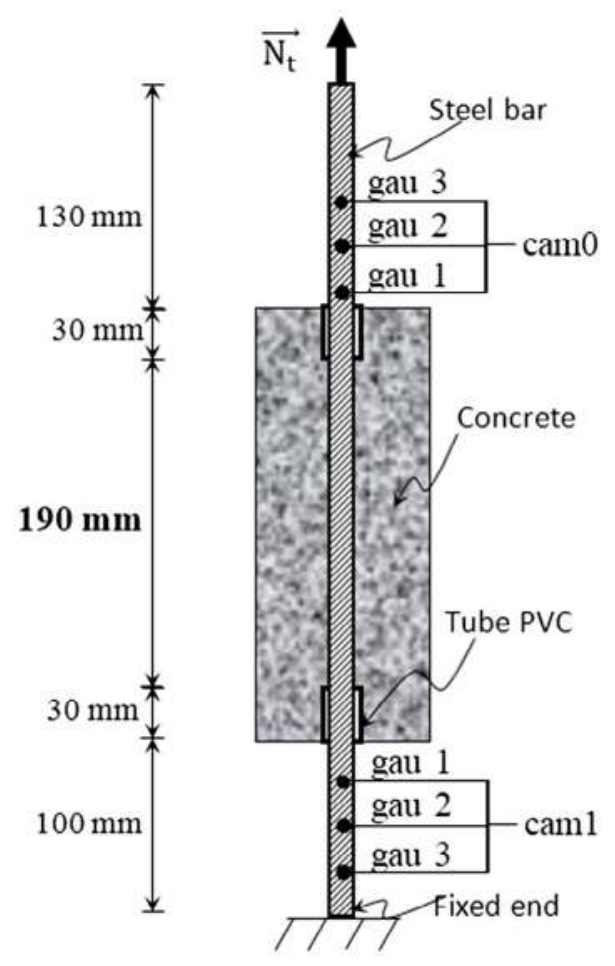

Figure 11. Tie-rods in tension. 
$(\mathrm{RH})$ of $95 \%$. Twenty four hours after casting, specimens were stripped off from the molds and kept for curing in lime water, under a temperature condition of $20{ }^{\circ} \mathrm{C}$ for 28 days.

After 28 days, tensile tests on reinforced concrete ties are carried out with a hydraulic machine with a capacity of $200 \mathrm{kN}$.

The lower free part of the rods was fixed while the other free part was subjected to a tensile load $N_{t}$ with a constant displacement kinetic of $1 \mathrm{~mm} / \mathrm{min}$ (Figure 11).

Two cameras (cam 0 and cam 1), were also used in order to measure the displacement of both free parts of the rebar (gau 1, gau 2 and gau 3) (Figure 11). The obtained informations allow us to plot the stress strain diagram $(\sigma-\varepsilon)$ of each short tie.

\subsection{Experimental results and analyzes}

The contribution of concrete is studied (in function of the adhesion) in a tie rod by measuring the difference between:

$$
\Delta \varepsilon=\varepsilon_{s n}-\varepsilon_{t}
$$

where $\varepsilon_{s n}$ and $\varepsilon_{t}=\Delta l_{t} / l_{t}$ represent, at the same instant, the relative elongations respectively of the steel assumed to be nude and the tie rod under the force $N_{t}$.

We present in Figure 12, the $\sigma-\varepsilon$ curves of tie-rods with diameters equal to HA8 (THA8) and HA12 (THA12).

The relation 25 provides an overview of the variation of adhesion between steel and concrete. The plotting of the curve $\Delta \varepsilon$ as a function of loading (represented here in Figure 13 by the stress in the steel) shows:

- For THA8 $(\Delta \varepsilon 8)$, the 'mobilized' adhesion in the tie rod increases linearly up to the force $N_{t}=16 \mathrm{kN}$, or a normal stress in the steel rebar of $\sigma_{s n}=319 \mathrm{MPa}$. The relative deformation of the tie rod is then $\varepsilon_{t}=8.5 .10^{-5}$, which corresponds to $\Delta \varepsilon 8=1.51 .10^{-3}$ . From this level of loading, the slope decreases considerably (Figures 12 and 13). The modulus of elasticity of the tie rod is slightly greater than that of the steel rebar.

- For THA12 ( $\Delta \varepsilon 12)$, the adhesion mobilized between the steel and the concrete in the tie rod increases linearly up to the load $N_{t}=15.7 \mathrm{kN}$, which corresponds to a normal stress in the steel rebar $\sigma_{s n}=139 \mathrm{MPa}$. At this moment, the relative deformation of the tie rod is equal to $\varepsilon_{t}=3.84 .10^{-4}$, which corresponds to $\Delta \varepsilon 12=3 \cdot 12 \cdot 10^{-4}$. A reduction in the adhesion between the steel and the concrete is then observed (Figures 12 and 13) and the modulus of elasticity of the tie rod is close to that of the steel. With the plasticization of the steel $\left(\sigma_{s n}=450 \mathrm{MPa}\right)$, the deterioration of the adhesion appears.

\subsection{Deductions of $\psi_{1}$ and $\psi_{2}$ values of the proposed laws}

At the beginning of loading, phase 1, the experimental curves (Figure 12) are approximated by taking the expression 26 as the value of the coefficient $\psi_{1}$. The other parameters $(1-\alpha)$ and $\gamma$ take into account, respectively, the confinement and the coating.

$$
\psi_{1}=\frac{1-\bar{\rho}}{\gamma \cdot(1-\alpha)} \quad \text { with }\left\{\begin{array}{lll}
\gamma=1 & \text { if } c \geq 5 . \emptyset & (\text { or } \rho<1 \%) \\
\gamma=\left(\frac{\emptyset}{c}\right)^{(1+\alpha)} & \text { if } c<5 . \emptyset & (\text { or } \rho \geq 1 \%)
\end{array}\right.
$$




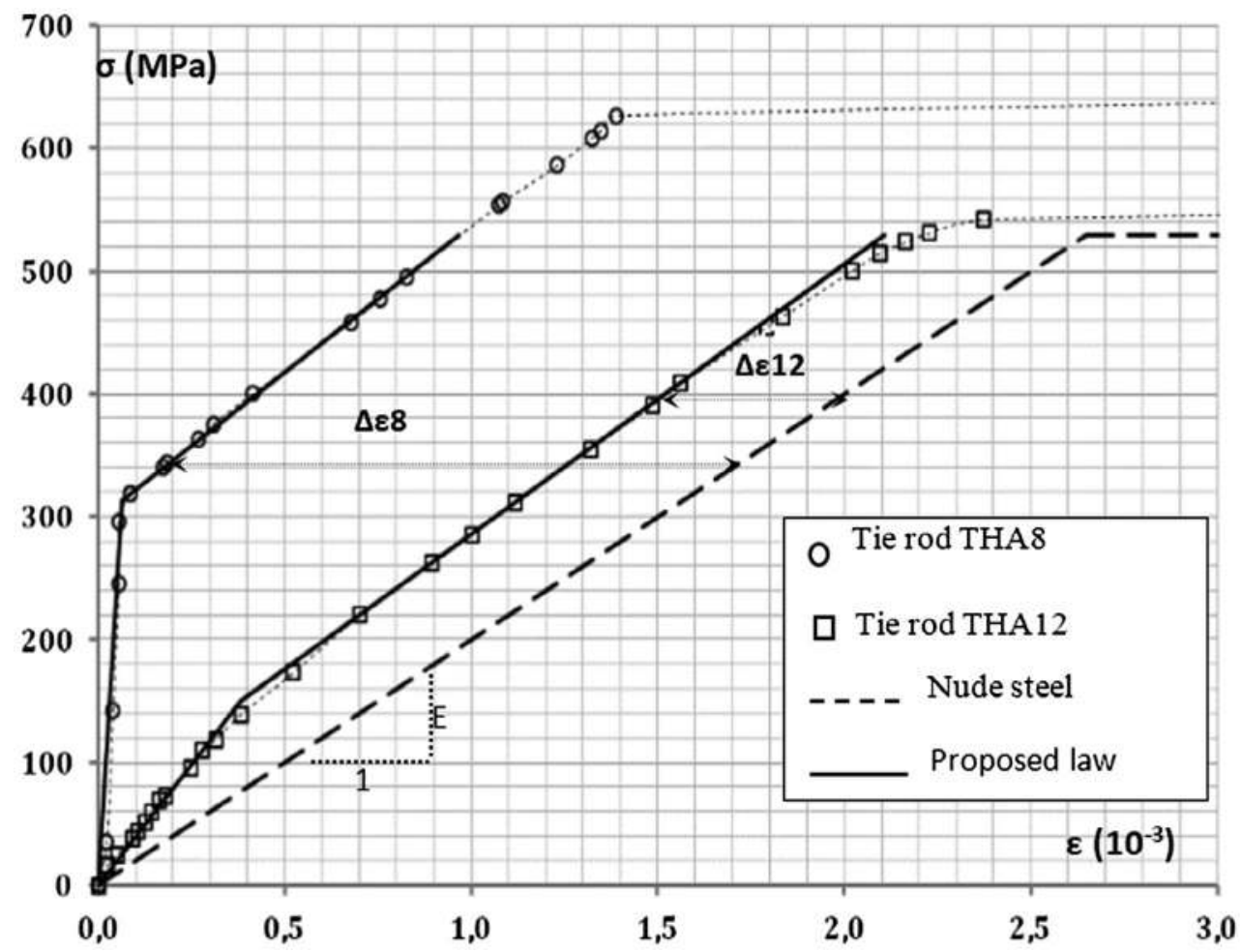

Figure 12. Diagrams $\sigma-\varepsilon_{t}$ of tie-rodsTHA8 and THA12.

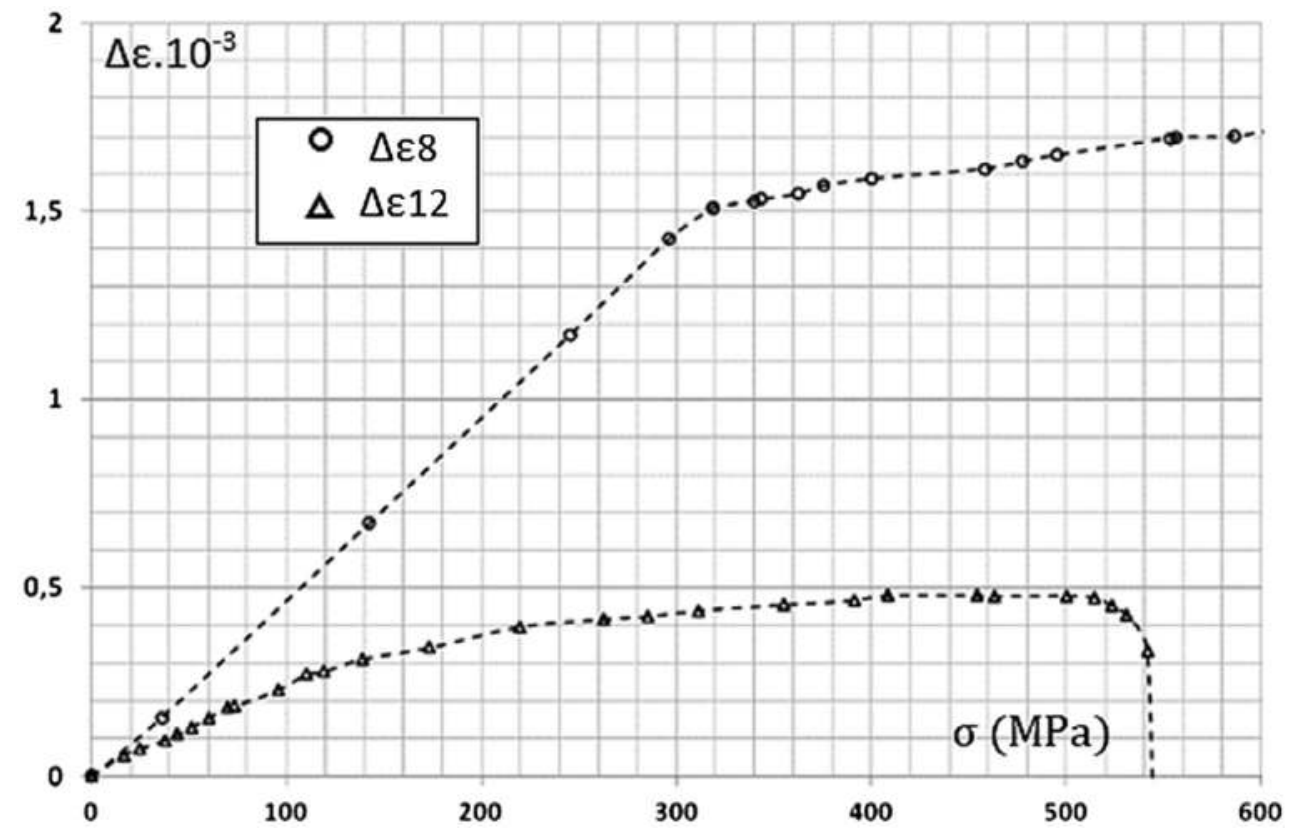

Figure 13. Diagrams $\Delta \varepsilon_{t}-\sigma$ of tie-rodsTHA8 and THA12. 
Table 6. Fictitious steel laws for short tie-rods without major cracks THA8.

\begin{tabular}{|c|c|c|c|c|}
\hline \multicolumn{5}{|c|}{ RC concrete Short ties with HA8 rebar (THA8) without principal cracking } \\
\hline$E_{f 1}(\mathrm{MPa})$ & $\sigma_{s n L}(\mathrm{MPa})$ & $\varepsilon_{s f L}\left(10^{-5}\right)$ & $E_{f 2}(\mathrm{MPa})$ & $\varepsilon_{s f e}\left(10^{-4}\right)$ \\
\hline \multirow[t]{2}{*}{$4.842 .10^{6}$} & 313.5 & 6.470 & $2.4 .10^{5}$ & 9.679 \\
\hline & $\begin{array}{r}\sigma=4.84 \\
\sigma=2.4 .1\end{array}$ & $\begin{array}{l}\text { if } \quad 0 \leq \varepsilon \\
\text { if } \quad 6.470\end{array}$ & $9.679 .10^{-4}$ & \\
\hline
\end{tabular}

Table 7. Fictitious steel laws for short tie-rods without major cracks THA12.

RC concrete Short ties with HA12 rebar (THA12) without principal cracking

\begin{tabular}{|c|c|c|c|c|}
\hline$E_{f 1}(\mathrm{MPa})$ & $\sigma_{s n L}(\mathrm{MPa})$ & $\varepsilon_{s f L}\left(10^{-4}\right)$ & $E_{f 2}(\mathrm{MPa})$ & $\varepsilon_{\text {sfe }}\left(10^{-3}\right)$ \\
\hline \multirow[t]{2}{*}{$3.932 .10^{5}$} & 150.9 & 3.840 & $2.2 .10^{5}$ & 2.107 \\
\hline & $\left\{\begin{array}{c}\sigma=3.932 \cdot 10^{5} . \varepsilon \\
\sigma=2 \cdot 2 \cdot 10^{5} . \varepsilon+66.52\end{array}\right.$ & $\begin{array}{l}\text { if } \quad 0 \leq \\
\text { if } \quad 3.840\end{array}$ & $2.107 .10^{-3}$ & \\
\hline
\end{tabular}

As a first approximation for the second phase, after maximum mobilization of the adhesion and its degradation we can take for the coefficient $\psi_{2}$, relation 27 :

$$
\left\{\begin{array}{lll}
\psi_{2}=0,9 & \text { if } c \geq 5 . \emptyset \quad & (\text { or } \rho<1 \%) \\
\psi_{2}=0,8 & \text { if } c<5 . \emptyset & (\text { or } \rho \geq 1 \%)
\end{array}\right.
$$

For the examples treated, THA 8 and THA12, with the data of Tables 3 and 5 and the relationships 14 to 18, 26 and 27, the equations in Tables 6 and 7 are obtained.

The representation of these theoretical curves in continuous line is illustrated, Figure 12.

\section{Conclusions}

- In the estimation of the adhesion peak $\tau_{1}$, of the $\tau-g$ law proposed by the European Concrete Committee, the coefficient ' $a$ ' can be replaced by its equivalent as a function of $\alpha$ so as to keep the same confinement parameter (see Relation 24).

- The raw (unconventional) characteristic values of the $\tau-g$ law of the first curvilinear curve proposed by the European Concrete Committee can be estimated in the pull out tests at the begining of the curve by the relations proposed here (Relations 21 and 22).

- For the pull out tests, under the same conditions, the order of magnitude of the maximum peak of adhesion does not depend on the percentage of steel because the adherent side surface of the bar to the concrete is all the greater as the perimeter is.

- The length of the tie-rods here does not allow an adhesion mobilization capable of creating a crack. The introduction length must not exceed half that of the tie-rod.

- The fictitious module slope of steel is higher the lower the percentage of steel. After a certain level of loading (maximum mobilization of the adhesion), the slope decreases and approaches that of the bare steel (10 to 20\%). At the approach of the elastic normal stress, this slope declines, this is partly explained by the Poisson effect. 
- The proposed laws, here, of simple analytic expressions, for short tie-rods without main cracks, suitably approach the test curves. However, other contributions are needed to improve this approach.

- It is clear that each steel-concrete mixture must include, after the granulometric analysis and the concrete formulation, a specific 'pull-out' study to be able to deduce the tie rods behavior.

- The results obtained in this study will serve to better understand the behavior of tie-rods in general (Fictitious diagram of steel and concrete, spacing of cracks, crack openings, ...). Indeed, during this last phase, the tie rod is composed of 'short tie rods without main cracks' object of this study.

\section{Nomenclature}

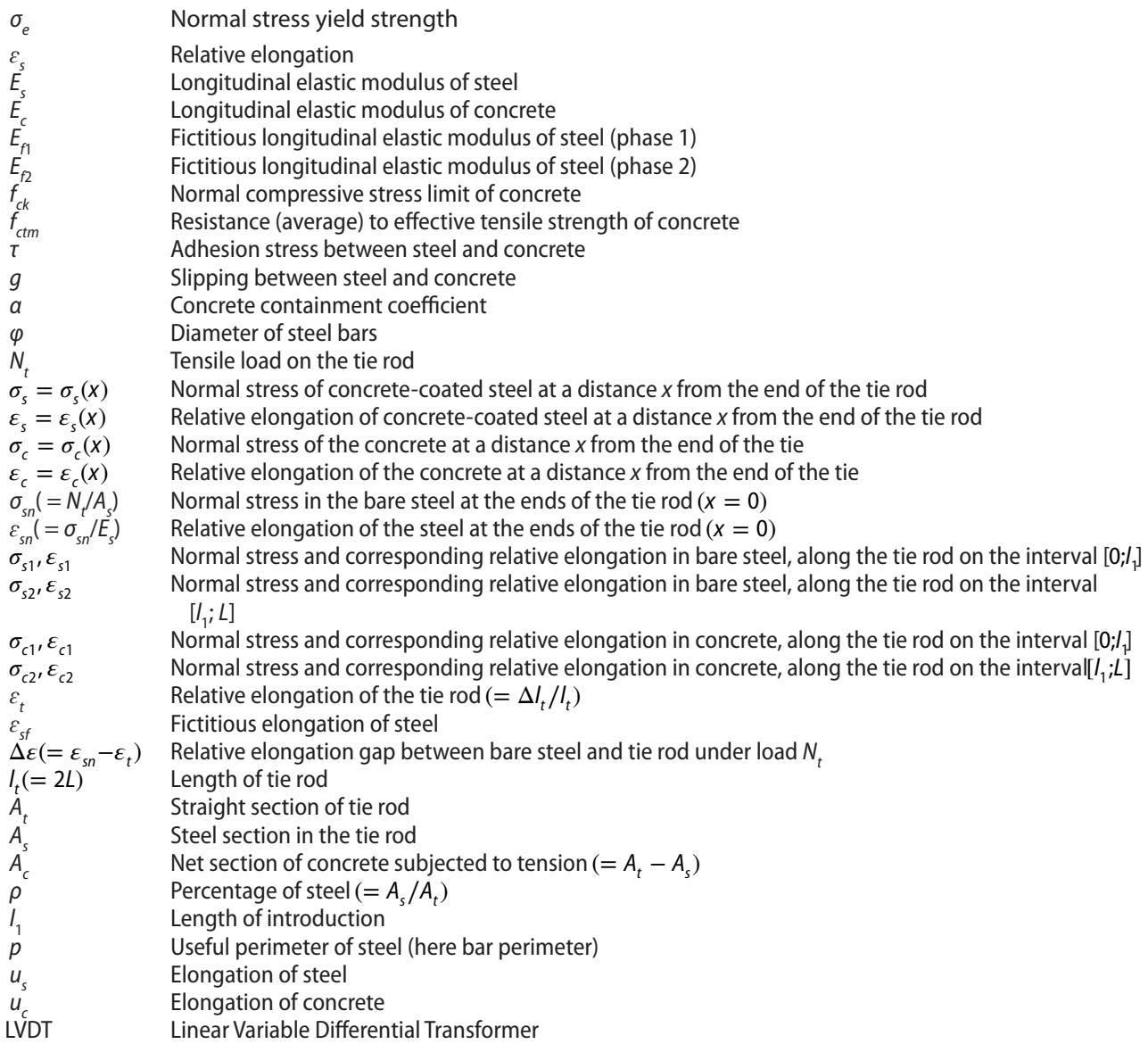

\section{Disclosure statement}

No potential conflict of interest was reported by the authors. 


\section{References}

[1] Brice MLP. Idées générales sur la fissuration du béton armé et du béton précontraint [General ideas on the reinforced concrete cracking and prestressed concrete]. Annales ITBTP; 1964. p. 198: French.

[2] CEB-FIP Model Code. Comité Euro-international du Béton-Fédération Internationale de la Précontrainte. London: Thomas Telford Ltd; 1990. p. 1993.

[3] Balazs GL. Cracking analysis based on slip and bond stresses. ACI Mater J. 1993;90(4):340-348.

[4] Chaussin R. Bases de la théorie de la fissuration, Fissuration et durabilité du béton [Cracking theory basics, cracking and concrete durability]. Rev Fr Génie Civ. 1998;2:243-254. French.

[5] Saad M, Kachi MS, Bouafia Y, et al. Influence du pourcentage d'acier sur le comportement du béton tendu fissuré: Calcul de l'ouverture des fissures par le biais de "l'acier fictif" [Steel percentage Influence on the cracked tensioned concrete behavior: crack opening calculation by means of "fictitious steel"]. Eur J Environ Civ Eng. 2010;14(3):303-327.French.

[6] Grelat A. Calcul non linéaire des ossatures en béton armé [Nonlinear calculation of reinforced concrete frames] [dissertation]. France: Pierre and Marie Curie University; 1978. French.

[7] Quast U. Zur Mitwirkung des Betons in der Zugzone. Beton-Stahlbetonbau. 1981;76(10):247250.

[8] Vecchio FJ, Collins MP. The modified compression-field theory for reinforced concrete elements subjected to shear. ACI J Proc. 1986;83(2):219-231.

[9] Fouré B. Déformations limites des armatures tendues et du béton comprimé pour le calcul sismique des structures [Limit deformations of tension reinforcement and compressed concrete for the structures seismic calculation]. VI Colloque national de l'Association Française de génie Para-Sismique. 2003:67-74. French.

[10] Espion B, Provost M, Halleux P. Rigidité d'une zone tendue de béton armé [Rigidity of a reinforced concrete tensile zone]. Matér Constr. 1985;18:185-191.

[11] Kwak HG, Song JY. Cracking analysis of RC members using polynomial strain distribution function. Eng Struct. 2002;24:455-468.

[12] Saad M. Influence du pourcentage d’acier sur le comportement Post - fissuration du béton armé en traction[Steel percentage influence on the post-cracking behavior of reinforced concrete in tension] [dissertation]. Algeria: Université Mouloud Mammeri de Tizi Ouzou; 2011.

[13] Bae BI, Choi HK, Choi CS. Bond stress between conventional reinforcement and steel fibre reinforced reactive powder concrete. Constr Build Mater. 2016;112:825-835.

[14] Metelli G, Plizzari GA. Influence of the relative rib area on bond behaviour. Mag Concr Res. 2014;66(6):277-294.

[15] Casanova A, Jason L, Davenne L, et al. Confinement effects on the steel-concrete bond strength and pull-out failure. Eng Fract Mech. 2013;97:92-104.

[16] Murcia D, Andreas S. SHING PB. bond strength and cyclic bond deterioration of large-diameter bars. ACI Struct J. 2013;110(4):659.

[17] Tastani SP, Pantazopoulou SJ. Reinforcement and concrete bond: state determination along the development length. J Struct Eng. 2013;139(9):1567-1581.

[18] Mang C, Jason L, Davenne L. A new bond slip model for reinforced concrete structures: validation by modelling a reinforced concrete tie. Eng Comput. 2015;32(7):1934-1958.

[19] Alam SY, Lenormand T, Loukili A, et al. Measuring crack width and spacing in reinforced concrete members. 7th International conference on Fracture Mechanics of Concrete and Concrete Structures (FraMCoS-7); 2010. p. 377-382.

[20] Carino NJ, Clifton JR. Prediction of cracking in reinforced concrete structures; 1995. (Report NISTIR). p. 5634.

[21] Bernardi P, Michelini E, Minelli F, et al. Experimental and numerical study on cracking process in RC and R/FRC ties. Mater Struct. 2016;49:261-277.

[22] Mang C, Jason L, Davenne L. Crack opening estimate in reinforced concrete walls using a steel-concrete bond model. Arch Civ Mech Eng. 2016;16(3):422-436.

[23] Zhandarov S, Mäder E. Analysis of a pull-out test with real specimen geometry. Part II: the effect of meniscus. J Adhes Sci Technol. 2014;28(1):65-84. 
[24] Zhandarov S, Mäder E. Analysis of a pull-out test with real specimen geometry. Part I: matrix droplet in the shape of a spherical segment. J Adhes Sci Technol. 2013;27(4):430-465.

[25] Casanova A, Jason L, Davenne L. Bond slip model for the simulation of reinforced concrete structures. Eng Struct. 2012;39:66-78.

[26] Handika N, Casaux GG, Sellier A. Influence of interface zone behaviour in reinforced concrete under tension loading: an analysis based on modelling and digital image correlation. Proceedings of XIII International Conference on Computational Plasticity. Fundand Applications Held in Barcelona Spain; 2015 Sept 1-3; p. 122-133.

[27] Eligehausen R, Popov EP, Bertero VV. Local bond stress-slip relationships of deformed bars under generalized excitations. Proceeding of 7th European Conference on Earthquake Engineering; 1982. p. 69-80.

[28] Saad M, Bouafia Y, Kachi MS. Contribution à lévaluation d'ouverture des fissures dans les éléments en béton armé [Contribution to evaluation of cracks opening in reinforced concrete elements]. Ann Bâtim Trav Public Ed ESKA. 2014;130:1214-1224.French.

[29] Giuriani E. On effective axial stiffness of a bar in cracked concrete. Proceedings of Bond in Concrete; Scotland; 1982. p. 107-126.

[30] Rehm G. The fundamental law of bond. Proceeding of the Symposium on Bond Crack Formation in Reinforced Concrete; Stockholm; 1957. p. 491-498.

[31] Soretz S, Holzenbein H. Influence of Rib Dimensions of Reinforcing Bars on Bond and Bendability. ACI J. 1979;76(1):111-128.

[32] Martin H, Noakowsky P. Verbundverhalten von Betonstählen - Untersuchung auf der Grundlage von Ausziehversuchen. Dtsch Aussch Für Stahlbeton. 1981;319:99-175.

[33] Caetano LF, Silva BV, Gomes LE, et al. Bond strength and rib geometry: a comparative study of the influence of deformation patternns on anchorage bond strength. 3rd fib International Congress; Washington (DC); May 2010. 